OPEN ACCESS

Edited by:

Nadia Bertin,

Plantes et Système de Cultures

Horticoles (INRA), France

Reviewed by:

Ana Maria Gomez-Caravaca,

University of Granada, Spain

Panagiotis Kalaitzis,

Mediterranean Agronomic Institute

of Chania, Greece

${ }^{*}$ Correspondence:

Rosario Muleo

muleo@unitus.it

tPresent address:

Marco Cirilli,

Department of Agricultural and Environmental Sciences,

University of Milan, Milan, Italy

Specialty section:

This article was submitted to Crop Science and Horticulture, a section of the journal

Frontiers in Plant Science

Received: 20 February 2017

Accepted: 19 April 2017

Published: 09 May 2017

Citation:

Cirilli M, Caruso G, Gennai C,

Urbani S, Frioni E, Ruzzi M,

Servili M, Gucci R, Poerio E and

Muleo RM (2017) The Role

of Polyphenoloxidase, Peroxidase,

and $\beta$-Glucosidase in Phenolics

Accumulation in Olea europaea $L$.

Fruits under Different Water Regimes.

Front. Plant Sci. 8:717.

doi: 10.3389/fpls.2017.00717

\section{The Role of Polyphenoloxidase, Peroxidase, and $\beta$-Glucosidase in Phenolics Accumulation in Olea europaea L. Fruits under Different Water Regimes}

\author{
Marco Cirillit', Giovanni Caruso², Clizia Gennai², Stefania Urbani³, Eleonora Frioni', \\ Maurizio Ruzzi ${ }^{4}$, Maurizio Servili ${ }^{3}$, Riccardo Gucci'2, Elia Poerio ${ }^{4}$ and Rosario Muleo ${ }^{1,5 *}$ \\ 1 Laboratorio di Ecofisiologia Molecolare delle Piante Arboree, Dipartimento di Scienze Agrarie e Forestali, Università degli \\ Studi della Tuscia, Viterbo, Italy, ${ }^{2}$ Dipartimento di Scienze Agrarie, Alimentari e Agro-ambientali, Università di Pisa, Pisa, Italy, \\ ${ }^{3}$ Dipartimento di Scienze Agrarie, Alimentari ed Ambientali, Università degli studi di Perugia, Perugia, Italy, ${ }^{4}$ Dipartimento per \\ la Innovazione nei Sistemi Biologici, Agro-alimentari e Forestali, Università degli Studi della Tuscia, Viterbo, Italy, ${ }^{5}$ Tree and \\ Timber Institute, National Research Council of Italy, Sesto Fiorentino, Italy
}

Olive fruits and oils contain an array of compounds that contribute to their sensory and nutritional properties. Phenolic compounds in virgin oil and olive-derived products have been proven to be highly beneficial for human health, eliciting increasing attention from the food industry and consumers. Although phenolic compounds in olive fruit and oil have been extensively investigated, allowing the identification of the main classes of metabolites and their accumulation patterns, knowledge of the molecular and biochemical mechanisms regulating phenolic metabolism remains scarce. We focused on the role of polyphenoloxidase (PPO), peroxidase (PRX) and $\beta$-glucosidase ( $\beta$-GLU) gene families and their enzyme activities in the accumulation of phenolic compounds during olive fruit development (35-146 days after full bloom), under either full irrigation (FI) or rain-fed (RF) conditions. The irrigation regime affected yield, maturation index, mesocarp oil content, fruit size, and pulp-to-pit ratio. Accumulation of fruit phenolics was higher in RF drupes than in FI ones. Members of each gene family were developmentally regulated, affected by water regime, and their transcript levels were correlated with the respective enzyme activities. During the early phase of drupe growth (35-43 days after full bloom), phenolic composition appeared to be linked to $\beta$-GLU and PRX activities, probably through their effects on oleuropein catabolism. Interestingly, a higher $\beta$-GLU activity was measured in immature RF drupes, as well as a higher content of the oleuropein derivate 3,4-DHPEA-EDA and verbascoside. Activity of PPO enzymes was slightly affected by the water status of trees during ripening (from 120 days after full bloom), but was not correlated with phenolics content. Overall, the main changes in phenolics content appeared soon after the supply of irrigation water and remained thereafter almost unchanged until maturity, despite fruit growth and the progressive decrease in pre-dawn leaf water potential. We suggest that enzymes involved in phenolic catabolism in the olive fruit have a differential sensitivity to soil water availability depending on fruit developmental stage.

Keywords: enzyme activities, phenols, secoiridoids, catabolism, olive, oleuropein, relative transcript level, water deficit 


\section{INTRODUCTION}

Over the last 20 years, the world consumption of olive oil has increased by $54 \%$ (International Olive Council [IOC], 2016), mostly due to a growing consumption in countries outside of the Mediterranean region. An increasing body of evidence suggests that the beneficial effects of VOO arise not only from its balanced fatty acid composition, but also from the presence of bio-active minor components such as tocopherols and phenolic compounds. Olive phenolic compounds have antioxidant properties and affect organoleptic properties of the olive fruit and oil.

The phenolics composition of olive fruits and derived VOOs is affected by many factors, namely cultivar, fruit development, climate conditions, and cultural practices (Ryan and Robards, 1998; Servili et al., 2007a; Tura et al., 2008). Several studies have focused on changes in the phenolics composition and content during fruit development until ripening (Amiot et al., 1986; Ryan et al., 1999; Alagna et al., 2012; Talhaoui et al., 2015). Secoiridoids, which include oleuropein, ligstroside, and their aglycon derivates $p$-HPEA-EA (ligstroside aglycon) and 3,4-DHPEA-EA (oleuropein aglycon isomer), dialdehydic forms of elenolic acid (3,4-DHPEA-EDA and $p$-HPEA-EDA), phenylethanoids such as tyrosol ( $p$-HPEA) and hydroxytyrosol (3,4-DHPEA), and verbascoside (a phenylpropanoid) are the main phenols in olive fruit, whereas flavonoids (rutin, luteolin, and cyanidin) represent only a minor fraction (Servili et al., 2004). The total phenol content is highest in immature drupes and gradually decreases during fruit development, although the rate of change varies depending on cultivar and environmental conditions (Monteleone et al., 1995; Romani et al., 1999; Rotondi et al., 2004; Talhaoui et al., 2015). Oleuropein and its derivative 3,4-DHPEA-EDA are the main bisphenols in olive mesocarp (Amiot et al., 1986; Alagna et al., 2012). During fruit growth, oleuropein progressively decreases concomitantly with the increase of 3,4-DHPEA-EDA. Some cultivars are also able to synthesize demethyloleuropein, which increases during ripening (Sivakumar et al., 2007; Alagna et al., 2012). Other secoiridoids, such as ligstroside ( $p$-HPEA-EDA), hydroxytyrosol (3,4-DHPEA), and tyrosol ( $p$-HPEA) follow the same decreasing trend as oleuropein during fruit maturation and ripening (Servili et al., 1999, 2004; Morelló et al., 2004), whereas the verbascoside content does not follow an unequivocal pattern (Amiot et al., 1986; Ryan et al., 2002; Alagna et al., 2012). Despite this knowledge, molecular and biochemical mechanisms regulating the accumulation of specific phenolic metabolites in the olive fruit are still far from being clear. Candidate genes involved in the biosynthesis of secoiridoids, phenylpropanoids, and flavonoids have recently been identified in Olea europaea (Alagna et al., 2009; Iaria et al., 2016). Nevertheless, several steps in the secoiridoid biosynthetic pathways remain unknown, as well as the general role of specific enzymatic classes, including the polyphenoloxidase (PPO), peroxidase (PRX), and $\beta$-glycosidase $(\beta$-GLU) families. The quantity and localization of in different fruit tissues affect the phenolic composition and oil quality of VOO during extraction (Luaces et al., 2007; Servili et al., 2007a). Endogenous glycosidase and esterase activities were hypothesized to play a pivotal role in the regulation of oleuropein hydrolysis (Amiot et al., 1989; Gutierrez-Rosales et al., 2010, 2012). Recently, several members of the $\beta$-glucosidase family have been found in proteomic and transcriptomic studies (Corrado et al., 2012; Bianco et al., 2013). An olive $\beta$-glucosidase (Oe $\beta$-GLU) able to deglycosilate oleuropein with high affinity has recently been isolated and functionally characterized (Koudounas et al., 2015).

Water availability represents the main limiting factor for growth and yield of crops of the Mediterranean region. A wide array of physiological responses, signals and genes are triggered in response to drought (Shao et al., 2008; Krasensky and Jonak, 2012). When the water stress signal reaches a threshold value, it determines morphological and physiological changes, including the production of reactive oxygen species (ROS) that act as an alarm to induce plant survival responses (Cruz de Carvalho, 2008). As phenolic compounds have strong antioxidant properties, a role in the protection against ROS during water stress adaptation has been long suggested (Ramakrishna and Ravishankar, 2011). Olive trees are typically adapted to long periods of high temperatures and drought during the summer (Lavee et al., 1991). Soil water availability dramatically affects the concentration of phenolic compounds during fruit development (Servili et al., 2007b; Caruso et al., 2014). In Greek cultivars, severe water stress induced an increase in total phenol content, mainly due to a rise in oleuropein content (Petridis et al., 2012). A positive relationship between total phenol content and antioxidant activity has also been detected, suggesting that phenols could play a relevant role in the protection against the effects of drought (Petridis et al., 2012). The effect of three different irrigation water regimes on analytical parameters of olive oil was evaluated in cultivars 'Leccino' and 'Frantoio' (Servili et al., 2007b; Caruso et al., 2014). Full irrigation (FI) decreased the concentration of total phenol and $o$-diphenol in VOOs, with wide differences in the concentration of the aglycone derivate of oleuropein. In olive trees of cultivar 'Arbequina' subjected to four irrigation management approaches, at different stages of fruit development, the highest content of total phenols, hydroxytyrosol acetate, 3,4-DHPEA-EDA, p-HPEA-EDA, 3,4DHPEA-EA, $o$-diphenols, tyrosyl elenolate ( $p$-HPEA-EA), and total secoiridoids was detected in trees stressed from the end of fruit drop to the end of July (Del Campo and García, 2013). Fruit ripening and irrigation treatments have been also found to induce considerable variation in the concentrations of secoiridoid derivatives of hydroxytyrosol and tyrosol in VOO of cultivars 'Cornicabra' (Gümez-Rico et al., 2006), 'Souri' (Dag et al., 2008), and 'Cipressino' (Martinelli et al., 2013). Similar results were found in trees of cultivar 'Leccino', where the highest content of phenolic compounds was detected in rain-fed (RF) trees, although the transcript level of the PAL gene did not differ among the water regimes (Martinelli et al., 2012).

Since there are no reports providing molecular evidence concerning the role of gene families involved in the oxidative catabolism of phenolic compounds in olive fruit, we set up a field experiment to provide insight about the role of PPOs, PRXs, and $\beta$-GLUs in the accumulation of phenolic compounds in olive fruits during their development and ripening. We used an integrated approach at the molecular, biochemical, and metabolic 
levels to investigate the role of the above enzymes on phenolic metabolism in fruits when the water status was manipulated by imposing either FI or RF conditions to field-grown olive trees ('Frantoio').

\section{MATERIALS AND METHODS}

\section{Plant Material and Site Characteristics}

Experiments were conducted in a fully productive, irrigated olive ('Frantoio') orchard located at Venturina, Italy, in 2011. Olive trees had been planted at a spacing of $5 \mathrm{~m} \times 3.9 \mathrm{~m}$ in April 2003. The soil was a deep $(1.5 \mathrm{~m})$, sandy-loam (ISSS classification), consisting of $60 \%$ sand, $15 \%$ clay, and $25 \%$ silt. The climate at the study site was sub-humid Mediterranean (Caruso et al., 2013), with an annual mean temperature and annual rainfall of $15^{\circ} \mathrm{C}$ and $635 \mathrm{~mm}$, respectively (means of 21 years, 1990-2010). Climatic conditions over the study period were monitored using an iMETOS IMT 300 weather station (Pessl Instruments $\mathrm{GmbH}$, Weiz, Austria). Reference annual evapotranspiration $\left(\mathrm{ET}_{0}\right)$, calculated according to the PenmanMonteith equation, was $840 \mathrm{~mm}$. The year 2011 was hot and dry with annual and summer (21 June-22 September) precipitations of 197 and $18 \mathrm{~mm}$, respectively (Supplementary Figure S1). Cultural practices and monitoring of phenological parameters were performed as previously reported (Caruso et al., 2013). In 2011, full bloom, estimated as when $70 \%$ of inflorescences showed at least $50 \%$ of flowers open, occurred on 24 May. Three blocks, each consisting of two irrigation treatments (three plots per treatment) randomly distributed, were used for the trial. Each of the six plots included 12 trees arranged in three rows of four trees. Only the inner trees of the central row were used for monitoring the tree water status, and only four of the six trees per treatment were used for measurements and sampling.

\section{Irrigation and Tree Water Status}

Subsurface drip irrigation lines $\left(2.3 \mathrm{~L} \mathrm{~h}^{-1}\right.$ pressure-compensated drippers spaced at $0.6 \mathrm{~m}$ ), placed at a depth of $0.35-0.40 \mathrm{~m}$ and $0.8 \mathrm{~m}$ distance from the tree row, were used to supply $100 \%$ (FI) or $2 \%(\mathrm{RF})$ of water requirements calculated from reference evapotranspiration using a crop coefficient of 0.55 (Caruso et al., 2013). RF trees received a total of $33 \mathrm{~m}^{3} \mathrm{ha}^{-1}$ irrigation on three dates $[93,94$, and 113 days after full bloom (DAFB)], to avoid tree damage due to extreme water stress. Therefore, the RF condition was partially alleviated by three complementary irrigations because of the particularly dry year. The irrigation period lasted from 1st July to 26th September, and FI trees received water 4-5 days a week (3-7 h per day); the volume applied was $734 \mathrm{~m}^{3} \mathrm{ha}^{-1}$, corresponding to $1431 \mathrm{~L}$ per tree. Irrigation volumes were calculated on the basis of the effective evapotranspiration, and tree water status was determined by measuring pre-dawn leaf water potential (PLWP) during the dry season at 7-10 days intervals. Leaves were excised with a razor blade, immediately put in the chamber cylinder (Tecnogas, Pisa, Italy), which was then pressurized with nitrogen gas at a maximum rate of $0.02 \mathrm{MPa} \mathrm{s}^{-1}$ (Caruso et al., 2013). Fertigation was used to supply mineral nutrients in spring, before irrigation treatments were put into action. Each tree received a total of approx. $90 \mathrm{~g}$ of $\mathrm{N}, \mathrm{P}_{2} \mathrm{O}_{5}$, and $\mathrm{K}_{2} \mathrm{O}$.

\section{Fruit Growth and Production}

Five fruits per tree in the south-east sector of the canopy were identified prior to the beginning of irrigation and their volume measured non-destructively by water displacement using a graduated cylinder. Fruits were sampled for enzymatic studies and determination of phenolic compounds at 35, 43, 63, 77, $93,115,136$, and 146 DAFB and immediately frozen in liquid nitrogen. Frozen samples were finely ground in liquid nitrogen using a mortar and pestle and preserved at $-80^{\circ} \mathrm{C}$ until biochemical and molecular analyses was carried out. The number of fruits sampled at each date was adjusted to account for fruit growth and obtain sufficient material for further analysis. In particular, 20 (35 DAFB), 15 (43, 63, and $77 \mathrm{DAFB})$, and 10 $(93,115,136$, and $146 \mathrm{DAFB})$ fruits were sampled from each of the four trees per treatment. Immediately before harvest, which occurred 146 DAFB, 50 fruits were randomly sampled from around the canopy of each tree to measure average fruit weight. The same fruits were also scored based on the color of the exocarp and mesocarp using a 0-7 arbitrary scale to determine the maturation index (MI) according to standard methodology (Caruso et al., 2013). Each tree was harvested individually by hand. The total number of fruits per tree was calculated by dividing the crop yield by the average fruit weight. At harvest (146 DAFB), five fruits per tree, similar to those used for enzyme assays and phenolic concentrations, were destructively sampled and their fresh weight (FW) determined. The mesocarp was separated from the endocarp using a sharp blade, the FW of both tissues was measured, and then the dry weight (DW) was determined after oven drying at $70^{\circ} \mathrm{C}$ to constant weight. The oil content of the fruit mesocarp of five fruits per tree, previously sampled for fresh and dry weight determinations, was also measured at harvest by nuclear magnetic resonance using an Oxford MQC-23 analyser (Oxford Analytical Instruments Ltd., Oxford, UK) as previously reported by Caruso et al. (2013).

\section{High-Performance Liquid Chromatography (HPLC) Analysis of Phenolic Compounds}

Fruits samples were frozen in liquid nitrogen and stored at $-80^{\circ} \mathrm{C}$, and successively used for phenolic determination. The phenols were extracted from the olive pulp according to the procedure described by Servili et al. (2012) modified as follows: $5 \mathrm{~g}$ of frozen olive pulp was homogenized with $100 \mathrm{~mL}$ of $80 \%$ methanol containing $20 \mathrm{mg} \mathrm{L}^{-1}$ butylated hydroxytoluene (BHT); the extraction was performed in triplicate. After methanol removal, the aqueous extract was used for extraction by solidphase separation (SPE) of phenols. The SPE procedure was applied by loading a $1000 \mathrm{mg}$ Bond Elute Jr-C18 cartridge (Agilent Technologies, Santa Clara, CA, USA) with $1 \mathrm{~mL}$ of sample, using $50 \mathrm{~mL}$ of methanol as the eluting solvent. After solvent removal under vacuum at $30^{\circ} \mathrm{C}$, the phenolic extract was recovered and then dissolved in methanol $(1 \mathrm{~mL})$ and filtered through a polyvinylidene fluoride (PVDF) syringe filter 
$(0.2 \mu \mathrm{m})$. The HPLC analyses of the phenolic extracts were conducted according to the method of Selvaggini et al. (2006) with a reversed-phase column using an Agilent Technologies system Model 1100 (Agilent Technologies, Santa Clara, CA, USA) that was composed of a vacuum degasser, a quaternary pump, an autosampler, a thermostatted column compartment, a diode array detector (DAD), and a fluorescence detector (FLD). The C18 column used in this study was a Spherisorb ODS-1 $250 \mathrm{~mm} \times 4.6 \mathrm{~mm}$ with a particle size of $5 \mu \mathrm{m}$ (Waters, Milford, MA, USA); the injected sample volume was $20 \mu \mathrm{L}$. The mobile phase was composed of $0.2 \%$ acetic acid ( $\mathrm{pH} 3.1$ ) in water (solvent $\mathrm{A}) /$ methanol (solvent $\mathrm{B}$ ) at a flow rate of $1 \mathrm{~mL} \mathrm{~min}^{-1}$, and the gradient was changed as follows: $95 \% \mathrm{~A} / 5 \% \mathrm{~B}$ for $2 \mathrm{~min}, 75 \%$ $\mathrm{A} / 25 \% \mathrm{~B}$ over $8 \mathrm{~min}, 60 \% \mathrm{~A} / 40 \% \mathrm{~B}$ over $10 \mathrm{~min}, 50 \% \mathrm{~A} / 50 \% \mathrm{~B}$ over $16 \mathrm{~min}$, and $0 \% \mathrm{~A} / 100 \% \mathrm{~B}$ over $14 \mathrm{~min}$; this composition was maintained for $10 \mathrm{~min}$, then returned to the initial conditions and equilibration over $13 \mathrm{~min}$; the total running time was $73 \mathrm{~min}$. Lignans were detected by an FLD operated at an excitation wavelength of $280 \mathrm{~nm}$ and emission at $339 \mathrm{~nm}$, while the other compounds were detected by DAD at $278 \mathrm{~nm}$.

\section{HPLC Analysis of VOO Phenolic Compounds}

The extraction of VOO phenolic compounds was performed as reported by Montedoro et al. (1992). The HPLC analyses of the phenolic extracts were conducted according to the method of Selvaggini et al. (2014); for the detection of phenolic compounds, a DAD was employed with the wavelength set at $278 \mathrm{~nm}$.

\section{Enzyme Extraction and Activities}

Two hundred milligrams of fruit pulp frozen powder was suspended in $1 \mathrm{~mL}$ of an extraction buffer consisting of $50 \mathrm{mM}$ potassium phosphate, $1 \mathrm{mM}$ EDTA, $1 \mathrm{mM}$ PMSF, and 1\% (w/v) PEG4000, $\mathrm{pH}$ 6.2. The suspension was shaken at $2000 \mathrm{rpm}$ for $1 \mathrm{~h}$ at $4^{\circ} \mathrm{C}$, and the supernatant was recovered by centrifugation (12000 rpm for $15 \mathrm{~min}$ at $4^{\circ} \mathrm{C}$ ). The pellet was re-extracted, and the two supernatants were combined, filtered through a $0.45 \mu \mathrm{m}$ filter (Sartorius, Italy), and used for enzyme activity assays.

Polyphenoloxidase activity was measured at $25^{\circ} \mathrm{C}$, according to the method of Zouari-Mechichi et al. (2006), by monitoring oxidation of 2,6-dimethoxyphenol (2,6-DMP) spectrophotometrically $\left(\varepsilon_{469 \mathrm{~nm}}=27.5 \mathrm{mM}^{-1} \mathrm{~cm}^{-1}\right)$; the reaction mixture ( $1 \mathrm{~mL}$ final volume) consisted of $5 \mathrm{mM} 2,6-\mathrm{DMP}$ in McIlvaine buffer at $\mathrm{pH}$ 6.0. $\mathrm{PRX}$ activity was measured at $25^{\circ} \mathrm{C}$, according to the method of Makkar et al. (2001), by monitoring oxidation of 2,2'-azino-bis(3-ethylbenzothiazoline-6-sulfonic acid) (ABTS) spectrophotometrically $\left(\varepsilon_{420}=36.0 \mathrm{mM}^{-1} \mathrm{~cm}^{-1}\right)$; the reaction mixture ( $1 \mathrm{~mL}$ final volume) consisted of $5 \mathrm{mM}$ ABTS and $0.2 \mathrm{mM} \mathrm{H}_{2} \mathrm{O}_{2}$ in Mcllvaine buffer at $\mathrm{pH}$ 3.0.

$\beta$-glycosidase activity was measured at $25^{\circ} \mathrm{C}$, according to Romero-Segura et al. (2009), by monitoring formation of $p$-nitrophenol spectrophotometrically $\left(\varepsilon_{405}=0.553 \mathrm{mM}^{-1}\right.$ $\mathrm{cm}^{-1}$ ) due to hydrolysis of $p$-nitrophenyl- $\beta$-D-glucopyranoside ( $p$-NPG). The reaction mixture ( $1 \mathrm{~mL}$ final volume) consisted of $5 \mathrm{mM} p$-NPG in McIlvaine buffer at $\mathrm{pH}$ 6.0. All enzyme activities were expressed as IU per $\mathrm{g}(\mathrm{FW})$ fruit tissue.

\section{Identification of Putative Genes Coding for Enzymes of Phenols Degradation}

Sequences of transcripts coding for PPO, PRX, and $\beta-G L U$ genes were identified by a tBLASTn approach, implemented in BioLign $4.0^{1}$, using amino acid sequences of enzymes already characterized in other plant species, including Arabidopsis thaliana, Malus domestica Borkh., Vitis vinifera L., and Populus trichocarpa. A search for O. europaea orthologous genes was performed by exploring olive fruit ${ }^{2}$ (Alagna et al., 2009) and flower EST databases (Alagna et al., 2016). Identified transcripts were annotated by BLAST against the NCBI- $n r$ database and used as a query to retrieve genomic sequences of each gene from an advanced genome assembly of cultivar 'Leccino' (Olea Genome Project). Genomic sequences were aligned with EST clusters to reconstruct the full-length ORF tentative consensus. Specific primers were designed by using Primer3 software ${ }^{3}$ (Supplementary Table S1).

\section{Amino Acid Sequence Comparisons and Phylogenetic Analysis}

The full predicted amino acid sequences of candidate genes were used to reconstruct the phylogeny with their homologs from others species. Alignments were performed using the ClustalW2 algorithm ${ }^{4}$ with default parameters and GeneDoc software. Gene models for multiple alignment analysis were obtained from the Phytozome V11.0 database ${ }^{5}$ (Supplementary Table S2). A rooted tree was reconstructed using the neighborjoining method in MEGA6 software (Tamura et al., 2013). Tree nodes were evaluated by bootstrap analysis of 1500 replicates (pairwise deletion, uniform rates, and Poisson correction options). Intracellular localization was inferred for each protein by the TargetP1.1 server ${ }^{6}$.

\section{Real-Time Quantitative PCR Expression Analysis}

Total RNA was extracted from fruit tissues, following the guidelines of a modified protocol of Doyle and Doyle (1990). Samples were DNase treated using an RNeasy Plant Mini Kit (Qiagen, Cat. No. 74904, Italy), following the manufacturer's instructions. RNA purity was evaluated by agarose gel electrophoresis and quantified using a QUBIT $^{\circledR} 2.0$ Fluorometer (Invitrogen, Cat. No. Q32866, Italy). First-strand cDNA was synthesized using Ready-To-GO ${ }^{\mathrm{TM}}$ RT-PCR Beads (GE Healthcare ${ }^{\mathrm{TM}}$ Illustra $^{\mathrm{TM}}$, Cat. No. 27-9267-01, Italy), following the manufacturer's guidelines. Real-time PCR analysis was conducted using the thermal cycler LC480II ${ }^{\circledR}$ (Roche, Italy). Each reaction $(20 \mu \mathrm{L})$ contained $10 \mu \mathrm{L}$ of LightCycler 480 SYBR Green I Master (Roche, Cat. No. 04707516 001, Italy), $0.5 \mu \mathrm{M}$ of each primer, $1 \mu \mathrm{L}$ of cDNA, and $7 \mu \mathrm{L}$ of PCR-grade water.

\footnotetext{
${ }^{1}$ http://biolign.software.informer.com/4.0/

${ }^{2}$ http://140.164.45.140/oleaestdb/search.php

${ }^{3}$ http://www.Primer3.com

${ }^{4}$ http://www.ebi.ac.uk/Tools/msa/clustalw2/

${ }^{5}$ https://phytozome.jgi.doe.gov/pz/portal.html

${ }^{6}$ http://www.cbs.dtu.dk/services
} 
The PCR reaction was conducted using the following conditions: $95^{\circ} \mathrm{C}$ for $10 \mathrm{~min} ; 45$ cycles at $94^{\circ} \mathrm{C}$ for $20 \mathrm{~s}, 59^{\circ} \mathrm{C}$ for $30 \mathrm{~s}$, and $72^{\circ} \mathrm{C}$ for $30 \mathrm{~s}$; followed by a melting cycle from $65-95^{\circ} \mathrm{C}$. Real-time quantitative PCR was performed using three biological replicates, with three technical replicates for each sample. Data were expressed with the $2^{\Delta \mathrm{Cp}}$ method (Kubista et al., 2006) using the geometric means of the elongation factor-1 alpha (OeEF1- $\alpha$, no. AM946404.1) and actin genes as endogenous reference genes for the normalization of transcript abundance. After PCR amplification, all products were sequenced to confirm their identity.

\section{RESULTS}

\section{Water Status and Yield Components}

The PLWP of the FI trees was usually maintained at approx. $-1 \mathrm{MPa}$ by irrigation. The PLWP dropped below $-1 \mathrm{MPa}$ three times and temporarily reached $-1.43 \mathrm{MPa}$ at $99 \mathrm{DAFB}$ during the irrigation period due to pump failure (Figure 1A). The PLWP of RF trees decreased progressively with increasing seasonal drought and reached very low values of -3.70 and $-3.99 \mathrm{MPa}$ at 109 and 142 DAFB (Figure 1A). Fruits from FI trees grew according to an almost linear pattern (Figure 1B). The size of FI fruits was greater than that of RF ones starting from 87 DAFB until harvest, when fruit volume of RF fruits was only $70 \%$ that of FI fruits (Figure 1B). Fruit yield of FI trees was higher $(227 \%)$ and significantly different from that of RF trees (Table 1). The number of fruits of FI trees was higher, but not significantly different, than that of RF trees, and this difference disappeared if the number of fruits per tree was expressed on a trunk cross-sectional area basis (Table 1). Significant differences in fruit FW were found between the two irrigation regimes; the maturation index (pigmentation of skin and pulp) was delayed in FI trees (Table 1). The oil yield of the RF treatment was $41 \%$ of that of FI trees.

Trees subjected to substantial water deficit (RF) had fruit measurements significantly lower than those for FI trees for all fruit parameters, except the endocarp DW (Table 2). The mesocarp, endocarp, and whole fruit FW of FI trees was 182, 130 , and $162 \%$ of those of the RF trees. The meso-to-endocarp ratio, the FW to DW ratio, and the mesocarp moisture were significantly higher $(136,126$, and $130 \%$, respectively) in fruits from FI trees compared with fruits from RF trees (Table 2).

\section{Phenolic Composition in Fruit and VOO}

Total phenols content (TPC), calculated as the sum of phenolic fractions on a mesocarp FW basis $\left[\mathrm{mg}(\mathrm{g} \mathrm{FW})^{-1}\right.$ ], showed a decreasing trend during fruit development, independently of the irrigation regime (Figure 2A). At maturity (146 DAFB), TPC was significantly higher in drupes of the RF trees than in those of the FI trees [24.7 vs. $14.8 \mathrm{mg}(\mathrm{g} \mathrm{FW})^{-1}$, respectively] (Supplementary Table S3). Differences in TPC between the two treatments were already evident at early stages of drupe development (43-65 DAFB) and were thereafter maintained without major changes until fruit maturity. Notably, the TPC content was higher in mature RF drupes on a DW basis (Table 3). As for individual fractions 3,4-DHPEA-EDA, verbascoside, and

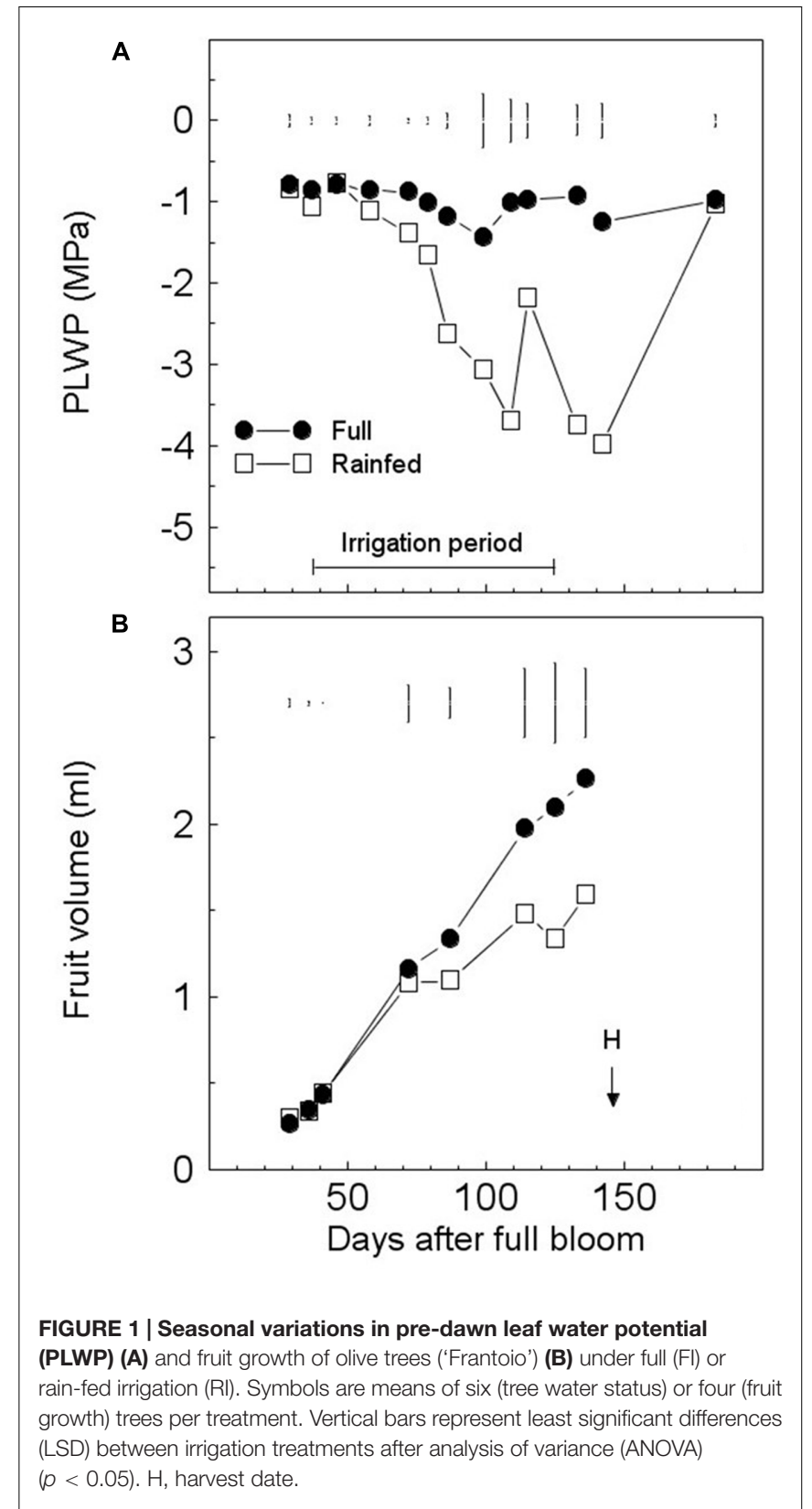

oleuropein contributed the most to the difference between mature fruits of FI and RF trees (Table 3). 3,4-DHPEA-EDA and verbascoside increased from 35 to $63 \mathrm{DAFB}$, but both tended to decrease later (Figures 2C,D and Supplementary Table S3). The oleuropein content was higher at the beginning of drupe development (from 35 to 43 DAFB) [60\% of phenol fraction: $41.5 \mathrm{mg}\left(\mathrm{g} \mathrm{FW}^{-1}\right]$ and after that strongly decreased, reaching a plateau at about 77 DAFB, under both water regimes (Figure 2B and Supplementary Table S3). The simple phenols 3,4-DHPEA and $p$-HPEA accounted for less than $3 \%$ of the phenol fraction analyzed (Figures 2E,F and Supplementary Table S3). Their content was higher at the early stage of fruit development and then declined sharply, apparently unaffected by water 
management. 3,4-DHPEA-EDA reached maximum content at 63 DAFB. Also, the lignans (+)-1-acetoxipinoresinol and (+)-1pinoresinol, accounting for less than $1.5 \%$ of the phenol fraction, were unaffected by water status (Supplementary Table S4).

The phenolic compounds concentration in VOO was also markedly affected by the soil water availability. The differences in TPC content were similarly significant in VOO, with contents in oils extracted from RF drupes more than twofold higher than those of oils extracted from FI drupes (Table 3). The 3,4-DHPEAEA, p-HPEA-EDA, and the sum of phenolic fractions in VOO obtained from RF trees were significantly higher (438, 257, and $223 \%$, respectively) than those from the FI trees.

\section{Changes in Enzyme Activities during Fruit Development}

Polyphenoloxidase activity remained low throughout fruit development until the onset of fruit ripening (from 43 to 115 DAFB), without significant changes between FI and RF trees (Figure 3A). PPO activity increased during ripening (from 136 to $146 \mathrm{DAFB}$ ), with higher values in FI tress (Figure 3A). In both FI and RF trees, the levels of PRX activity progressively decreased during the first 93 days of ripening before increasing in the following 50 days. In fruits from FI trees, the PRX activity at day 146 was twofold higher than that in fruits from RF trees (Figure 3B). A peak of $\beta$-GLU activity was detected at about 50 DAFB in fruits from both FI and RF treatments, then this activity declined to become almost undetectable after the pit-hardening stage (Figure 3C).

\section{Identification of Transcripts Putatively Involved in Phenols Catabolism}

A number of transcripts coding for PPO, PRX, and $\beta$-GLU enzymes and putatively expressed in fruit tissues have been identified.
Four full-length transcripts coding for $P P O$ genes were arbitrarily named OePPO1-like, 2-like, 3-like, and 4-like, after identification in a flower and fruit library (Supplementary Table S2). The isoforms were encoded by a single exon, as also reported in other plant species (Tran et al., 2012). Conceptual translation of the four putative $P P O$ sequences allowed identification of the conserved tyrosinase domain (Supplementary Figure S2), composed of the copper-binding sub-domains $\mathrm{CuA}$ and $\mathrm{CuB}$ and characterized by six conserved histidine residues that bond the two copper ions of the active site (Tran et al., 2012). Moreover, two domains with unknown function, DWL (Pfam12142) and KFDW (Pfam12143), previously identified in $P$. trichocarpa PPOs, were also present (Supplementary Figure S2). A chloroplast localization signal was identified in all four olive PPO genes, as also predicted in other species (Supplementary Table S5). Phylogenetic analysis grouped OePPO1-like, 2-like, and 4-like in a clade comprising several PPO members of Mimulus guttatus, while OePPO3-like seemed to be phylogenetically distant (Supplementary Figure S3). Class III peroxidases are heme-containing glycoproteins encoded by a multigene family (Hiraga et al., 2001). At least 61 members of class III peroxidase gene family were identified in a draft assembly of O. europaea cv. 'Leccino' genome (data not shown), 5 of which resulted the most represented in RNAseq libraries from olive fruit tissues. Active site residues of identified OePRXs contained the catalytic distal Arg38, His42 hydrogen-bonded to Asn70 (Supplementary Figure S4) (Smith and Veitch, 1998). Furthermore, we identified other conserved amino acid residues, such as Pro139, which putatively accepts a hydrogen bond from reducing substrates, and His170, which is coordinated to heme $\mathrm{Fe}^{3+}$ and hydrogen-bonded to Asp247. In OePRX42, the His70 was replaced by Ser70, and this substitution also occurred in other plant PRXs, such as A. thaliana PRX1 (Tognolli et al., 2002). Predicted side chain ligands to the distal and the proximal $\mathrm{Ca}^{2+}$ ions were also identified (Supplementary

TABLE 1 | Yield, yield components, yield efficiency (fruit yield/TCSA), and maturation index (MI) of olive trees ('Frantoio') subjected to full irrigation (FI) or rain-fed (RF) conditions.

\begin{tabular}{lccccccc}
\hline Irrigation & Fruit yield (g/tree) & Fruit yield/TCSA (g/dm $\left.\mathbf{~}^{-2}\right)$ & Fruits/tree & Oil yield (g/tree) & Fruit FW (g) & MI & Oil in mesocarp (\%/DW) \\
\hline $\mathrm{FI}$ & $8070 \mathrm{~b}$ & 3437 & 3255 & $1960 \mathrm{~b}$ & $2.5 \mathrm{~b}$ & $3.2 \mathrm{a}$ & $68.3 \mathrm{~b}$ \\
$\mathrm{RF}$ & $3559 \mathrm{a}$ & 2074 & 2311 & $792 \mathrm{a}$ & $1.5 \mathrm{a}$ & $4.0 \mathrm{~b}$ & $58.4 \mathrm{a}$ \\
$\mathrm{LSD}$ & 3339 & 1580 & 1454 & 985 & 0.2 & 0.4 & 2.0 \\
\hline
\end{tabular}

Values are means of four trees per treatment $(n=4)$. Different letters indicate least significant differences (LSD) between irrigation treatments after analysis of variance (ANOVA) within each year ( $P<0.05)$. TCSA, trunk cross-sectional area; FW, fresh weight; DW, dry weight.

TABLE 2 | Fresh weight and dry weight of fruit, mesocarp, and endocarp, meso-to-endocarp ratio, fruit FW/DW ratio, and mesocarp moisture of fruits sampled from olive trees ('Frantoio') subjected to FI or RF conditions.

\begin{tabular}{|c|c|c|c|c|c|c|c|c|c|}
\hline Irrigation & $\begin{array}{c}\text { Fruit } \\
\text { FW (g) }\end{array}$ & $\begin{array}{c}\text { Fruit } \\
\text { DW (g) }\end{array}$ & $\begin{array}{c}\text { Mesocarp } \\
\text { FW (g) }\end{array}$ & $\begin{array}{c}\text { Endocarp } \\
\text { FW (g) }\end{array}$ & $\begin{array}{c}\text { Mesocarp } \\
\text { DW (g) }\end{array}$ & $\begin{array}{c}\text { Endocarp } \\
\text { DW (g) }\end{array}$ & $\begin{array}{l}\text { Mesocarp to } \\
\text { endocarp } \\
\text { ratio (FW) }\end{array}$ & $\begin{array}{l}\text { FW/DW } \\
\text { fruit }\end{array}$ & $\begin{array}{l}\text { Mesocarp } \\
\text { moisture (\%) }\end{array}$ \\
\hline $\mathrm{FI}$ & $2.60 \mathrm{~b}$ & $1.42 b$ & $1.78 b$ & $0.82 b$ & $0.90 \mathrm{~b}$ & 0.52 & $2.16 \mathrm{~b}$ & $1.84 b$ & $49.0 \mathrm{~b}$ \\
\hline $\mathrm{RF}$ & $1.61 \mathrm{a}$ & $1.10 \mathrm{a}$ & $0.98 a$ & $0.63 b$ & $0.61 b$ & 0.49 & $1.59 a$ & $1.46 \mathrm{~b}$ & $37.6 a$ \\
\hline$\angle S D$ & 0.28 & 0.13 & 0.18 & 0.14 & 0.08 & 0.08 & 0.36 & 0.27 & 7.73 \\
\hline
\end{tabular}

Values are means of four trees per treatment $(n=4)$. Different letters indicate LSD between irrigation treatments ANOVA $(p<0.05)$. 

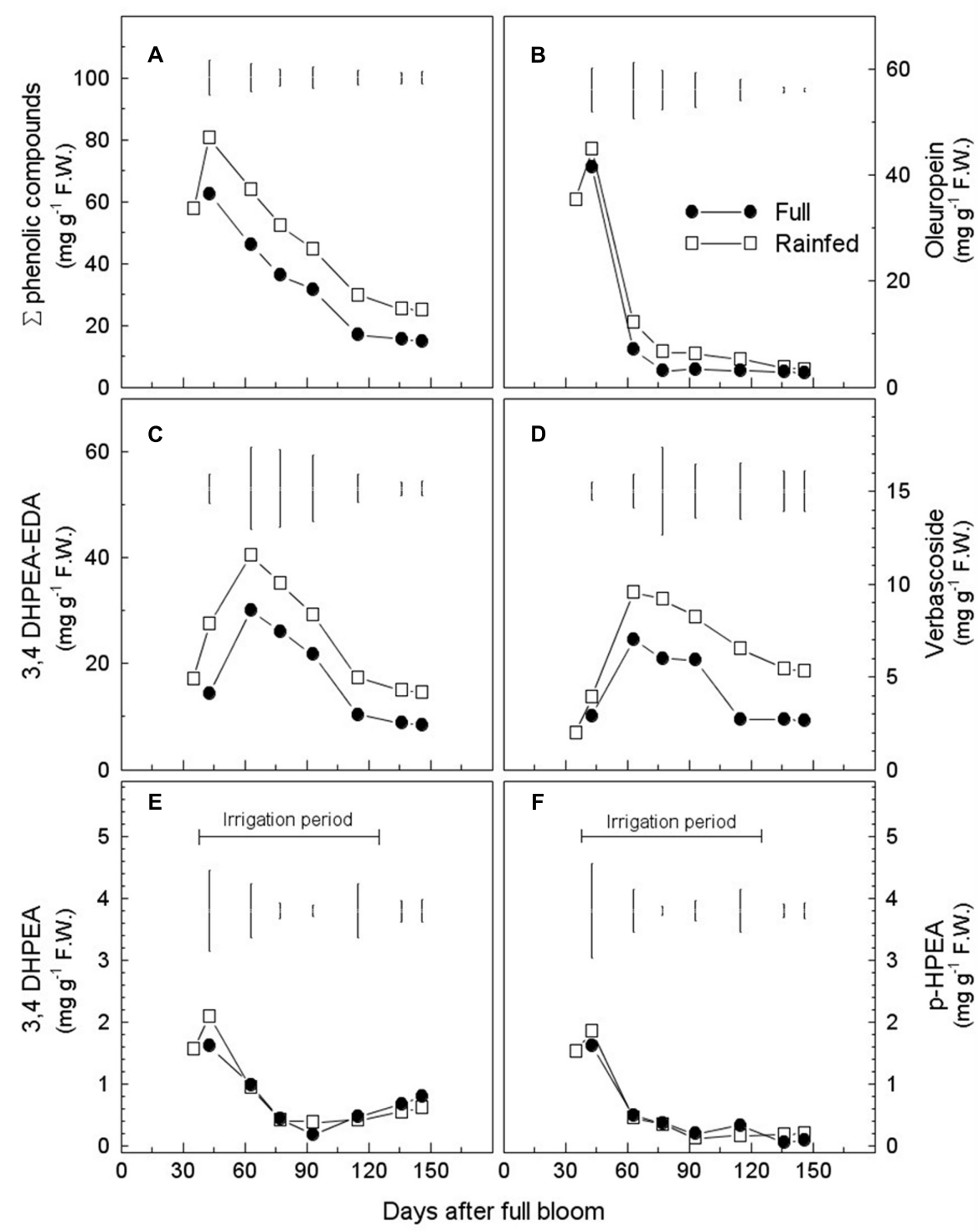

FIGURE 2 | Seasonal variations in phenolic compounds [ $\mathrm{mg}\left(\mathrm{g} \mathrm{FW}^{-1}\right]$ in mesocarp of fruits from fully irrigated (FI) and rain-fed (RF) olive trees during fruit development. Total phenol content is shown in (A), oleuropein in (B), 3,4-DHPEA-EDA in (C), verbascoside in (D), 3,4-DHPEA in (E) and p-HPEA in (F). Values are means of three trees for each irrigation treatment. Vertical bars represent LSD between irrigation treatments ANOVA $(p<0.05)$.

Figure S4). OePRXs contained eight conserved cysteine residues putatively involved in disulfide bridges and a buried salt bridge motif present in all class III PRXs (Welinder, 1992). Putative OePRXs were predicted as secretory proteins (Supplementary Table S6). Moreover, as in other species, OePRXs had several $\mathrm{N}$-linked glycans in the sequence motif Asn-X-Ser/Thr (Veitch, 2004). Phylogenetic analysis confirmed the similarity of the identified olive PRXs with other class III PRXs (Supplementary Figure S5).

Amino acid alignments of the four identified members of the olive glycoside hydrolase (GH) family 1 highlight the presence of the two glutamate residues embedded in the highly conserved motifs TF/LNEP (acid/base catalyst) and I/VTENG (nucleophile), except for Oeß-GLU46-like characterized by the motifs TVNEA/IHENG (Supplementary Figure S6). The analysis with TargetP v1.0 predicted that Oeß-GLU11 and 46-like are localized in extra-cellular space, while the localization of both Oe $\beta$-GLU12-like isoforms is uncertain (Supplementary Table S7). Phylogenetic analyses were performed to gain information about their putative substrates (Supplementary Figure S7). Oe $\beta$-GLU12-like1 and Oe $\beta$-GLU12like2, both belonging to the GH1 subgroup 12, cluster in a well-differentiated clade composed of the recently characterized Oe $\beta$-GLU, and RsSG and RsRG enzymes of Rauvolfia serpentina, 
TABLE 3 | Phenolic compounds in mesocarp of fruits [mg (g DW) ${ }^{-1}$ ] sampled at harvest (146 DAFB) and oils (mg kg ${ }^{-1}$ ) obtained from fruits sampled at the same data from olive trees subjected to FI or RF conditions.

\begin{tabular}{|c|c|c|c|c|c|c|}
\hline Irrigation & $p$-HPEA & 3,4-DHPEAz & Oleuropein & Verbascoside & 3-4 DHPEA-EDA & Sum of phenolic fractions \\
\hline \multicolumn{7}{|l|}{ Fruit } \\
\hline $\mathrm{FI}$ & 0.16 & 1.54 & 4.93 & 5.16 & 15.91a & $28.47 a$ \\
\hline $\mathrm{RF}$ & 0.34 & 0.99 & 5.40 & 8.57 & $23.56 b$ & $39.94 b$ \\
\hline$\angle S D$ & 0.40 & 0.58 & 1.22 & 4.24 & 4.36 & 7.88 \\
\hline \multicolumn{7}{|l|}{ Olive oil } \\
\hline $\mathrm{FI}$ & 13.6 & 2.0 & $28.3 a$ & $35.7 a$ & $80.4 a b$ & $167.5 \mathrm{a}$ \\
\hline $\mathrm{RF}$ & 10.7 & 3.9 & 124.2 & $92.0 \mathrm{~b}$ & 133.3b & $373.3 b$ \\
\hline$\angle S D$ & 5.1 & 3.0 & 8.8 & 12.77 & 40.81 & 59.1 \\
\hline
\end{tabular}

Values are means of three trees for each irrigation treatment. Different letters indicate LSD between irrigation treatments ANOVA ( $p<0.05)$.
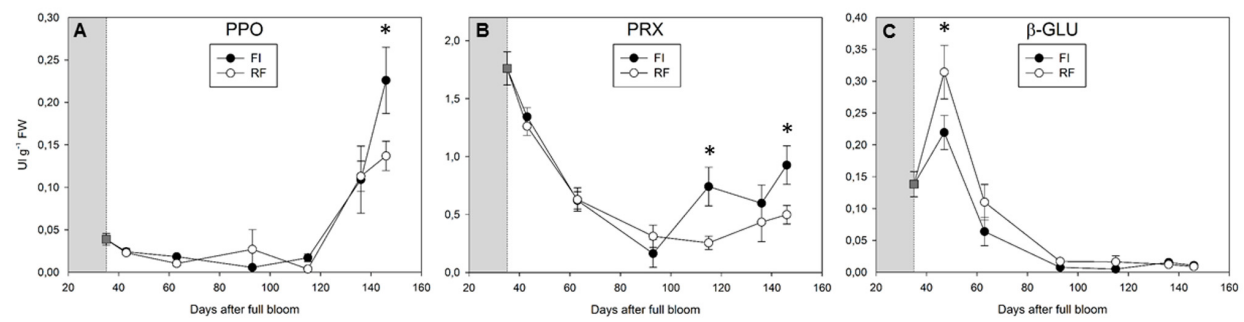

FIGURE 3 | Polyphenoloxidase (PPO) (A), peroxidase (PRX) (B), and $\beta$-glucosidase ( $\beta$-GLU) (C) activity detected in olive fruit of FI and RF trees. Dashed line indicates the beginning of treatment. Symbols and bars indicate the average and SD of four biological and two technical replications. Asterisks $\left({ }^{*}\right)$ indicate a significant statistical difference between FI and RF treatments at $p<0.01$ (Student's $t$-test).

involved in monoterpenoid indole alkaloids biosynthesis (Warzecha et al., 2000; Gerasimenko et al., 2002). It is unclear whether the two olive Oeß-GLU12 isoforms are different alleles of the same isoform, since $O e \beta-G L U$ is encoded by a single locus in olive cultivar 'Koroneiki' (Koudounas et al., 2015). Oe $\beta$-GLU46 belongs to a large subgroup composed of glucosidases putatively involved in the phenylpropanoids pathway and lignin biosynthesis. Consistent with this hypothesis, Oe $\beta$-GLU46 is predicted to be targeted to the extracellular space (Supplementary Table S7). Oe $\beta$-GLU11 belongs to the AtGLU11 subgroup, the members of which seem to work on different substrates, such as hydroxyisourate for the biosynthesis of the allantoin precursor in Glycine max (Raychaudhuri and Tipton, 2002).

\section{Relative Gene Expression}

The expression of OePPO genes was differently modulated along the stages of drupe development and appeared to be affected by plant water status. OePPO1 expression was high during young fruit development, decreased after 43 DAFB, and strongly increased again at the two late sampling dates (136 and 146 DAFB) (Figure 4A). This expression pattern may suggest that OePPO1 is the main enzymatic isoform active during ripening. Moreover, OePPO1 was expressed twofold more in drupes of FI trees. By contrast, OePPO2 showed the highest peak of transcripts during the pit-hardening phase (from 77 to 93 DAFB), with the maximum expression value in FI trees reached earlier than that in $\mathrm{RF}$ trees (Figure 4B). OePPO3 and $\mathrm{OePPO} 4$ were expressed at lower levels, although the former was up-regulated from 77 to
115 DAFB in fruits of FI trees and only at 93 DAFB in fruits of RF trees, whereas the latter gene was downregulated from 63 DAFB until the harvest of fruits (Figures 4C,D).

Among the Oeß-GLU genes analyzed, Oeß-GLU12.1 transcripts showed the highest magnitude and were essentially expressed early in drupe development (from 43 to 63 DAFB) (Figure 4E). The other isoform, Oeß-GLU12.2, showed two peaks, one at the beginning of drupe growth (35 DAFB) and the other near ripening (146 DAFB) (Figure 4F). Both Oeß-GLU12 genes showed higher transcript levels in FI trees. Oeß-GLU11 showed higher expression in young fruit that then increased again at ripening, more in FI drupes (Figure 4G). Oeß-GLU46 expression did not seem to be affected by either fruit development or water availability (Figure $4 \mathbf{H}$ ).

Transcript levels of all OePRX genes were higher during the earlier stages of fruit development and then sharply decreased. At ripening, OePRX17 and OePRX72 were barely detectable (Figures 5A,E), while $O e P R X 64$ and $O e P R X 55$ increased again, more in FI fruit (Figures 5B,D). OePRX42 showed an expression pattern similar to that of $\operatorname{OePRX17}$, although the reduction of transcript levels during fruit development was less drastic (Figure 5C).

\section{DISCUSSION}

We confirmed the general decrease in phenolics content during olive fruit development reported in previous work (Alagna et al., 2012) but, interestingly, each metabolite showed a specific pattern 

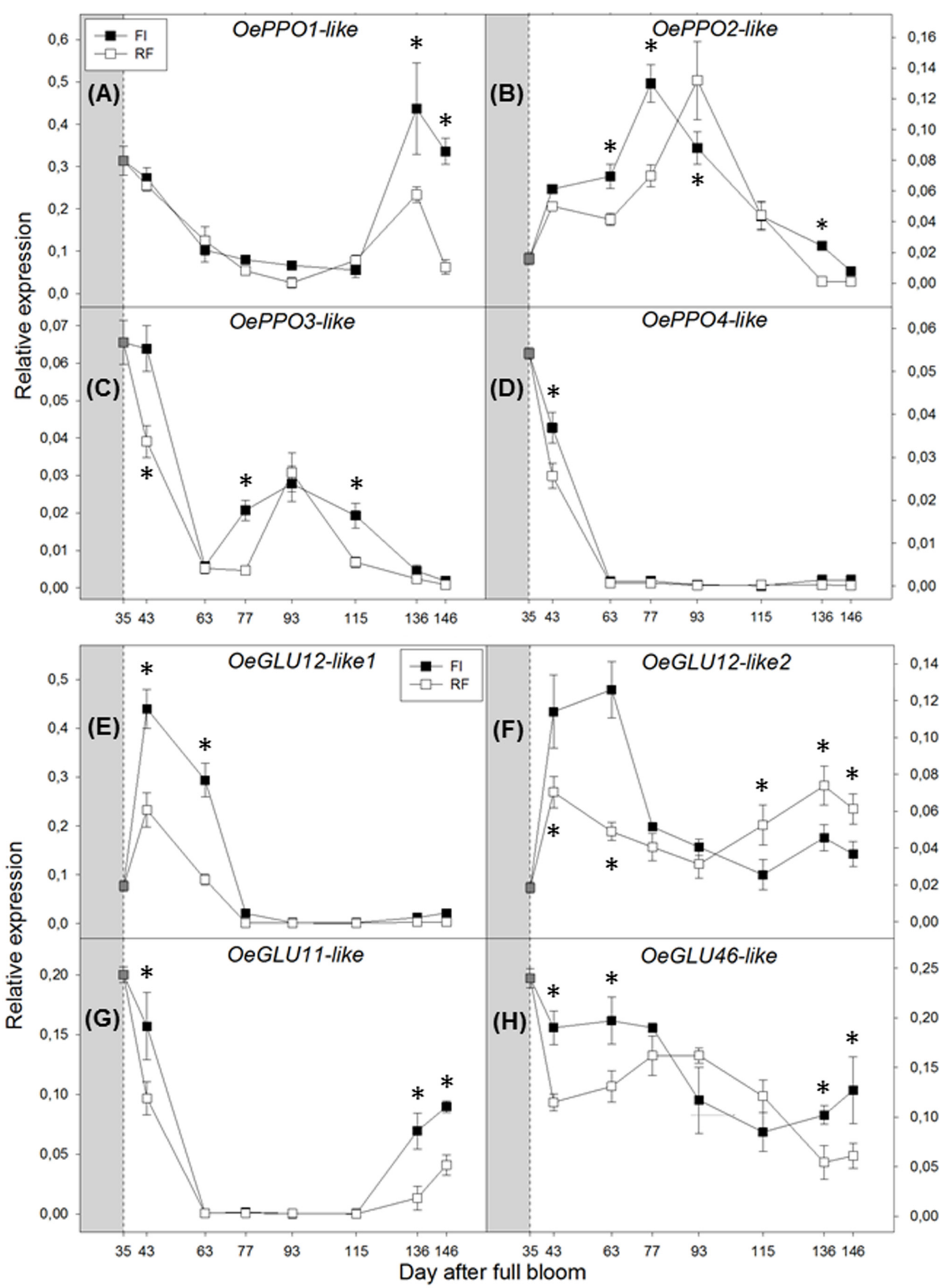

FIGURE 4 | Real-time quantitative PCR analysis of OePPO1-like (A), OePPO2-like (B), OePPO3-like (C), OePPO4-like (D), OeGLU12-like1 (E), OeGLU12-like-2 (F), OeGLU46-like (G), and OeGLU11-like (H), in Fl and RF trees. Dashed line indicates the beginning of treatment. Symbols indicate the average of four biological replications, and bars show $\pm \mathrm{SD}$. Asterisks $\left(^{*}\right)$ indicate a significant statistical difference between $\mathrm{Fl}$ and RF treatments at $p<0.01$ (Student's $t$-test).

(Figure 2). An inverse relationship between oleuropein content and its derivative 3,4-DHPEA-EDA appeared evident during early stages of fruit development. The up-regulation of both identified Oeß-GLU12-like isoforms, showing a high similarity with Oeß-GLU (involved in oleuropein deglycosylation), and the peak of $\beta$-GLU activity further supported their predominant role in the oleuropein catabolic processes occurring during early stages of fruit development and contributing to the composition of olive phenolics (Figures 3C, 4E,F). These results agree with those reported by Gutierrez-Rosales et al. (2010), who hypothesized that 3,4-DHPEA-EDA was formed via oleuropein by $\beta$-GLU activity. Transcription levels of OeGLU12-like1 and like2 were higher in FI trees, unlike enzyme activity and 3,4DHPEA-EDA content, which were both higher in RF trees. 


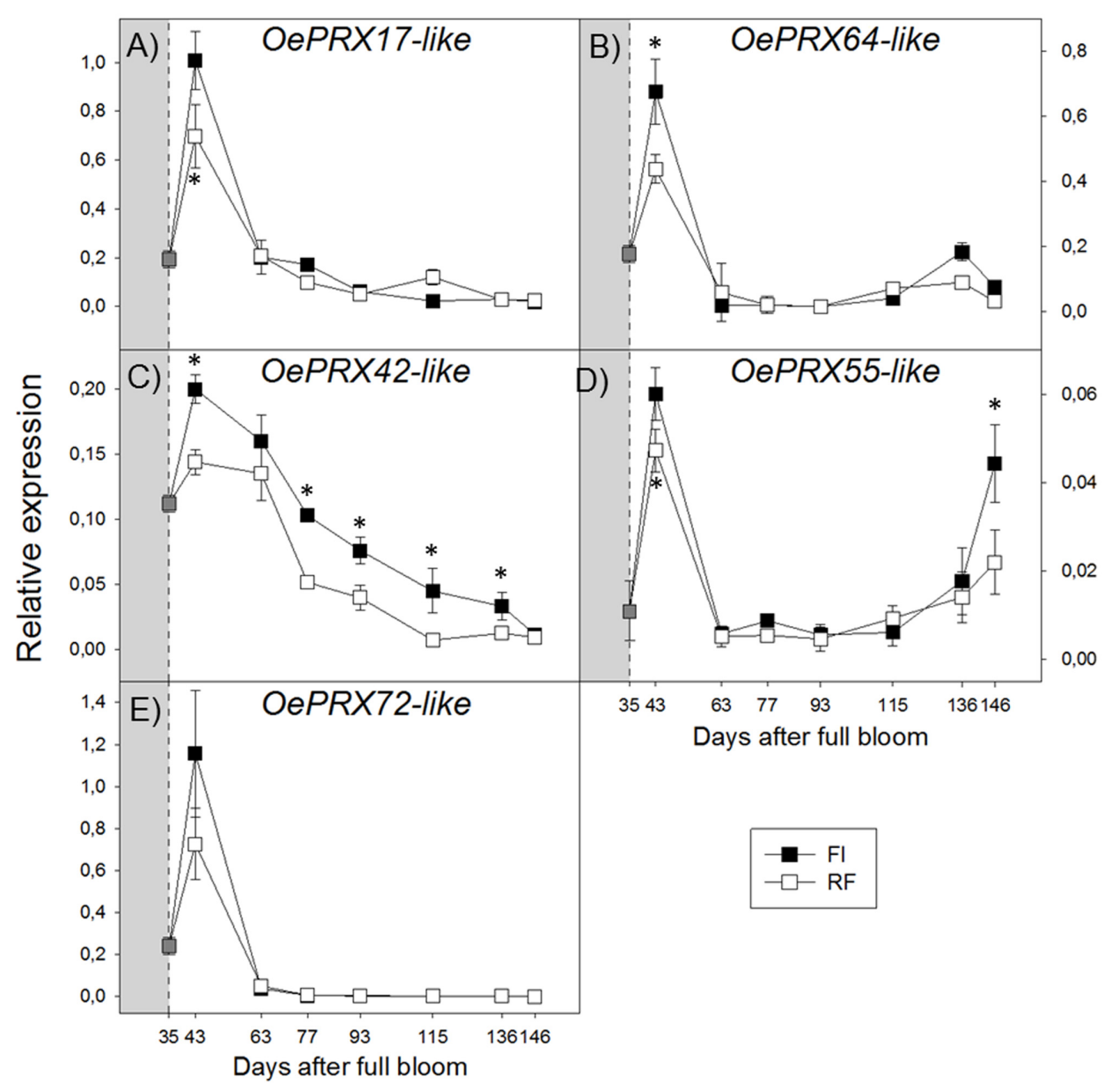

FIGURE 5 | Real-time quantitative PCR analysis of OePRX17-like (A), OePRX64-like (B), OePRX42-like (C), OePRX55-like (D), and OePRX72-like (E), in FI and RF trees. Dashed line indicates the beginning of treatment. Symbols indicate the average of four biological replications, and bars show \pm SD. Asterisks $\left({ }^{*}\right)$ indicate a significant statistical difference between $\mathrm{Fl}$ and RF treatments at $p<0.01$ (Student's $t$-test).

Although a positive effect of water deficit on GLU activity could be hypothesized, the identification of putative esterase enzyme(s) regulating 3,4-DHPEA-EDA biosynthesis will help to better elucidate this pathway and the effect of water availability.

The expression of olive PPO genes was affected by olive fruit developmental stages as well as plant water status (Figure 4). OePPO1 seems to be the main isoform during early fruit development and maturation (after 115 DAFB), whereas OePPO2 was mainly expressed during the pit-hardening period (from 77 to 93 DAFB). A relationship between the expression of olive $P P O$ genes and PPO activity appeared evident during fruit ripening (Figures 3A, 4), and a close relationship between drupe PPO activity and fruit developmental stage has already been observed in cultivar 'Zard', accompanied by differential expression of isoenzymes (Ebrahimzadeh et al., 2003). Significant changes in kinetic behavior of PPO were observed also during fruit maturation in cultivar 'Picual', and it was suggested that the assayed activity may be the result of the expression of different genes (Ortega-García et al., 2008). Transcript levels of
OePPO1 and PPO activity were higher in irrigated trees during advanced stages of fruit maturation, but gene expression and activity were not correlated with phenolic amount or specific metabolites, which remained stable during ripening. This agrees with the findings of Ortega-García et al. (2008), who showed that the increase in PPO activity during fruit ripening of cultivar 'Picual' did not parallel the variation in oleuropein concentration. Therefore, in intact olive drupes, PPO activity apparently plays a minor role in secoiridoid metabolism.

Peroxidases (Class III) oxidize phenolics as preferential substrates at the expense of peroxides. The highest levels of $O e P R X$ transcripts were detected from 35 to 43 DAFB. OePRX transcripts accumulation decreased sharply after the first stage of growth (Supplementary Figure S2). However, levels of OePRX64 and OePRX55 increased again in ripe fruits. In most cases, the expression levels were higher in FI trees than in RF trees, and we generally found a good correlation between $P R X$ transcript accumulation and PRX activity: the highest enzyme activity was detected early during fruit development (35 DAFB), subsequently 
it decreased and then increased again at maturation (Figure 3B). High levels of PRX activity have been found in olive seed, and the effect of this enzymatic activity on the VOO phenolic profile has been proved (Luaces et al., 2007). A PRX enzyme that binds specifically to pectic polysaccharides has been purified from black ripened olives ('Douro') (Saraiva et al., 2007), and more recently Tzika et al. (2009) have reported the partial purification of a PRX enzyme from 'Koroneiki' olive fruits that seems to be active toward some olive fruit phenols but inactive toward oleuropein. Contribution of PRX to the oxidation of phenols is generally limited by the availability of $\mathrm{H}_{2} \mathrm{O}_{2}$, which usually increases under stress conditions or tissue damage (Sharma et al., 2012). The expression pattern and activity of several PRX isoforms was well correlated with phenol content in immature fruits but seemed to be unaffected by water availability, since the levels of PRX activity were similar between FI and RF treatments. Considering that a direct involvement of PRXs in oleuropein oxidation has yet to be demonstrated, such activity does not appear to play a pivotal role in explaining the different phenolics contents found in immature drupes.

Water availability is one of the major factors affecting olive yield and quality of both table olives and olive oils, particularly in areas where long periods of summer drought occurs during fruit growth and development. It has been shown that water availability affects the content of olive phenolics in fruit and oil and that the increase in irrigation volumes is negatively correlated with secoiridoids content (Patumi et al., 1999, 2002; Tovar et al., 2001, 2002; Gümez-Rico et al., 2006; Servili et al., 2007b; Caruso et al., 2014). In our study, fruits and oils from RF trees had consistently higher phenolic contents than those from FI trees. The ratio of phenolic content between FI and RF trees was 71 and $45 \%$ in the mesocarp (DW basis) and VOO, respectively, indicating that the RF conditions probably increased the fraction of phenols transferring into VOO during extraction. Nonetheless, there are many intriguing issues that remain to be clarified. For example, differences in fruit phenolic contents arose soon after the beginning of irrigation (35-43 DAFB), when drupe size was not significantly different between FI and RF trees, and thereafter remained almost unchanged until maturity, despite the progressive decrease in PLWP and fruit enlargement. Therefore, we hypothesize that phenolic catabolism is particularly sensitive to water availability during early stages of drupe development, affecting oleuropein catabolism through the regulation of glucosidase activity. As already reported in other species, the timing of water deficit, and its intensity and duration, is crucial for assimilate partitioning between primary and secondary pathways (Ni et al., 2009; Ripoll et al., 2014). In olive fruits, moderate water deficit starting 63 DAFB had no effects on cell division, but reduced mesocarp cell expansion, FW, and, only slightly and later in the mature stage of development, DW, suggesting that different cellular processes are involved depending on the stage of fruit development (Gucci et al., 2009, 2011). Analogously, we hypothesize that a cross-talk is active between fruit development and cell water status for regulating the expression of genes and activity of enzymes playing a role in phenolic catabolism, but further studies are needed to clarify this point.

\section{CONCLUSION}

We have provided integrated evidence concerning the regulation and role of GLU, PRX, and PPO in the accumulation of phenolic compounds in olive fruits, suggesting a key role for $\beta$-GLU in oleuropein catabolism. Moreover, we provide the first detailed study on the effect of water availability on phenolics metabolism during fruit growth and ripening, suggesting that fruit response may vary depending on the developmental stage and the timing of water deficit. Knowledge of the genetic and physiological mechanisms underlying plant responses to the frequent succession of severe drought periods becomes a crucial factor, especially in optimizing irrigation management to achieve a balanced trade-off between olive oil yield and quality, and the saving of water resources.

\section{AUTHOR CONTRIBUTIONS}

RG, MS, MR, EP, MC, and RM developed the concept of the paper, wrote the paper, GC and CG performed eco-physiological analysis, collected and analysed meteorological data, MC and EF carried out qRT-PCR analyses and bioinformatic analyses, SU performed HPLC-polyphenolic analysis and quantification, and EF, EP, and MR performed enzymatic activities. All authors discussed and commented the manuscript.

\section{FUNDING}

This research was supported by the Project OLEA - Genomics and Breeding of Olive (D.M.27011/7643/10), funded from 'Ministero delle politiche agricole, alimentari e forestali,' Italy. The grant from 'Donazione Anna Maria Catalano - ONLUS,' Italy, also provided partial financial support. The funders had no role in study design, data collection and analysis, decision to publish, or preparation of the manuscript.

\section{SUPPLEMENTARY MATERIAL}

The Supplementary Material for this article can be found online at: http://journal.frontiersin.org/article/10.3389/fpls.2017.00717/ full\#supplementary-material 


\section{REFERENCES}

Alagna, F., Cirilli, M., Galla, G., Carbone, F., Daddiego, L., Facella, P., et al. (2016). Transcript analysis and regulative events during flower development in olive (Olea europaea L.). PLoS ONE 11:e0152943. doi: 10.1371/journal.pone.01 52943

Alagna, F., D’Agostino, N., Torchia, L., Servili, M., Rao, R., Pietrella, M., et al. (2009). Comparative 454 pyrosequencing of transcripts from two olive genotypes during fruit development. BMC Genom. 10:399. doi: 10.1186/14712164-10-399

Alagna, F., Mariotti, R., Panara, F., Caporali, S., Urbani, S., Veneziani, G., et al. (2012). Olive phenolic compounds: metabolic and transcriptional profiling during fruit development. BMC Plant Biol. 12:162. doi: 10.1186/1471-222912-162

Amiot, M. J., Fleuriet, A., and Macheix, J. J. (1986). Importance and evolution of phenolic compounds in olive during growth and maturation. J. Agric. Food Chem. 34, 823-826. doi: 10.1021/jf00071a014

Amiot, M. J., Fleuriet, A., and Macheix, J. J. (1989). Accumulation of oleuropein derivates during olive maturation. Phytochemistry 28, 67-69. doi: 10.1016/00319422(89)85009-5

Bianco, L., Alagna, F., Baldoni, L., Finnie, C., Svensson, B., and Perrotta, G. (2013). Proteome regulation during Olea europaea fruit development. PLoS ONE 8:e53563. doi: 10.1371/journal.pone.0053563

Caruso, G., Gucci, R., Urbani, S., Esposto, S., Taticchi, A., Di Maio, I., et al. (2014). Effect of different irrigation volumes during fruit development on quality of virgin olive oil of cv. Frantoio. Agric. Water Manag. 134, 94-103. doi: 10.1016/j. agwat.2013.12.003

Caruso, G., Rapoport, H. F., and Gucci, R. (2013). Long-term evaluation of yield components of young olive trees during the onset of fruit production under different irrigation regimes. Irrigation Sci. 31, 37-47. doi: 10.1007/s00271-0110286-0

Corrado, G., Alagna, F., Rocco, M., Renzone, G., Varricchio, P., Coppola, V., et al. (2012). Molecular interactions between the olive and the fruit fly Bactrocera oleae. BMC Plant Biol. 12:86. doi: 10.1186/1471-2229-12-86

Cruz de Carvalho, M. H. (2008). Drought stress and reactive oxygen species. Plant Signal. Behav. 3, 156-165. doi: 10.4161/psb.3.3.5536

Dag, A., Ben-Gal, A., Yermiyahu, U., Basheer, L., Nir, Y., and Kerem, Z. (2008). The effect of irrigation level and harvest mechanization on virgin olive oil quality in a traditional rain-fed 'Souri' olive orchard converted to irrigation. J. Sci. Food Agric. 88, 1524-1528. doi: 10.1002/jsfa.3243

Del Campo, M. G., and García, J. M. (2013). Summer deficit-irrigation strategies in a hedgerow olive cv. Arbequina orchard: effect on oil quality. J. Agric. Food Chem. 61, 8899-8905. doi: 10.1021/jf402107t

Doyle, J. J., and Doyle, J. L. (1990). Isolation of plant DNA from fresh tissue. Focus $12,13-15$.

Ebrahimzadeh, H., Motamed, N., Rastgar-Jazt, F., Montasser-Kouhsai, S., and Shokrap, E. H. (2003). Oxidative enzyme activities and soluble protein content in leaves and fruits of olives during ripening. J. Food Biochem. 27, 181-196. doi: 10.1111/j.1745-4514.2003.tb00276.x

Gerasimenko, I., Sheludko, Y., Ma, X., and Stöckigt, J. (2002). Heterologous expression of a Rauvolfia cDNA encoding strictosidine glucosidase, a biosynthetic key to over 2000 monoterpenoid indole alkaloids. Eur. J. Biochem. 269, 2204-2213. doi: 10.1046/j.1432-1033.2002.02878.x

Gucci, R., Caruso, G., Rapoport, H. F., and Lodolini, E. M. (2011). Irrigation differently affects endocarp and mesocarp growth during olive fruit development. Acta Hortic. 889, 297-302. doi: 10.17660/ActaHortic.2011. 889.35

Gucci, R., Lodolini, E. M., and Rapoport, H. F. (2009). Water deficit-induced changes in mesocarp cellular processes and the relationship between mesocarp and endocarp during olive fruit. Tree Physiol. 29, 1575-1585. doi: 10.1093/ treephys/tpp086

Gutierrez-Rosales, F., Romero, M. P., Casanovas, M., Motilva, M. J., and MínguezMosquera, M. (2010). Metabolites involved in oleuropein accumulation and degradation in fruits of Olea europaea L.: Hojiblanca and Arbequina varieties. J. Agric. Food Chem. 58, 12924-12933. doi: 10.1021/jf103083u

Gutierrez-Rosales, F., Romero, M. P., Casanovas, M., Motilva, M. J., and MínguezMosquera, M. (2012). $\beta$-Glucosidase involvement in the formation and transformation of oleuropein during the growth and development of olive fruits
(Olea europaea L. cv. Arbequina) grown under different farming practices. J. Agric. Food Chem. 60, 4348-4358. doi: 10.1021/jf205209y

Gümez-Rico, A., Salvador, M. D., La Greca, M., and Fregapane, G. (2006). Phenolic and volatile compounds of extra virgin olive oil (Olea europaea L. cv. Cornicabra) with regard to fruit ripening and irrigation management. J. Agric. Food Chem. 54, 7130-7136. doi: 10.1021/jf060798r

Hiraga, S., Sasaki, K., Ito, H., Ohashi, Y., and Matsui, H. (2001). A large family of class III plant peroxidases. Plant Cell Physiol. 42, 462-468. doi: 10.1093/pcp/ pce061

Iaria, D. L., Chiappetta, A., and Muzzalupo, I. (2016). A De novo transcriptomic approach to identify flavonoids and anthocyanins "Switch-Off" in olive (Olea europaea L.) drupes at different stages of maturation. Front. Plant Sci. 6:1246. doi: $10.3389 /$ fpls.2015.01246

International Olive Council [IOC] (2016). Market Newsletter. No 108 - September 2016. Available at: http://www.internationaloliveoil.org/news/view/686-year2016-news/762-marketnewsletter-september-2016

Koudounas, K., Banilas, G., Michaelidis, C., Demoliou, C., Rigas, S., and Hatzopoulos, P. (2015). A defence-related Olea europaea $\beta$-glucosidase hydrolyses and activates oleuropein into a potent protein cross-linking agent. J. Exp. Bot. 66, 2093-2106. doi: 10.1093/jxb/erv002

Krasensky, J., and Jonak, C. (2012). Drought, salt, and temperature stress-induced metabolic rearrangements and regulatory networks. J. Exp. Bot. 63, 1593-1608. doi: $10.1093 /$ jxb/err460

Kubista, M., Andrade, J. M., Bengtsson, M., Forootan, A., Jonák, J., Lind, K., et al. (2006). The real-time polymerase chain reaction. Mol. Aspects Med. 27, 95-125. doi: 10.1016/j.mam.2005.12.007

Lavee, H., Imeson, A. C., Pariente, S., and Benyamini, Y. (1991). The response of soils to simulated rainfall along a climatological gradient in an arid and semi-arid region. Catena Suppl. 19, 19-37.

Luaces, P., Romero, C., Gutierrez, F., Sanz, C., and Pérez, A. G. (2007). Contribution of olive seed to the phenolic profile and related quality parameters of virgin olive oil. J. Sci. Food Agric. 87, 2721-2727. doi: 10.1002/jsfa.3049

Makkar, R. S., Tsuneda, A., Tokuyasu, K., and Mori, Y. (2001). Lentinula edodes produces a multicomponent protein complex containing manganese (II)-dependent peroxidase, laccase and $\beta$-glucosidase. FEMS Microbiol. Lett. 200, 175-179. doi: 10.1016/s0378-1097(01)00159-8

Martinelli, F., Basile, B., Morelli, G., d'Andria, R., and Tonutti, P. (2012). Effects of irrigation on fruit ripening behavior and metabolic changes in olive. Sci. Hortic. 144, 201-207. doi: 10.1016/j.scienta.2012.07.012

Martinelli, F., Remorini, D., Saia, S., Massai, R., and Tonutti, P. (2013). Metabolic profiling of ripe olive fruit in response to moderate water stress. Sci. Hortic. 159, 52-58. doi: 10.1016/j.scienta.2013.04.039

Montedoro, G., Servili, M., Baldioli, M., and Miniati, E. (1992). Simple and hydrolyzable compounds in virgin olive oil. 1. Their extraction, separation and quantitative and semiquantitative evaluation by HPLC. J. Agric. Food Chem. 40, 1571-1576. doi: 10.1021/jf00021a019

Monteleone, E., Caporale, G., Lencioni, L., Favati, F., and Bertuccioli, M. (1995). Optimization of virgin olive oil quality in relation to fruit ripening and storage Dev. Food Sci. 37, 397-418. doi: 10.1016/S0167-4501(06)80168-8

Morelló, J. R., Romero, M. P., and Motilva, M. J. (2004). Effect of the maturation process of the olive fruit on the phenolic fraction of drupes and oils from arbequina, farga, and morrut cultivars. J. Agric. Food Chem. 52, 6002-6009. doi: $10.1021 /$ jf035300p

Ni, F. T., Chu, L. Y., Shao, H. B., and Liu, Z. H. (2009). Gene expression and regulation of higher plants under soil water stress. Curr. Genomics 10, 269-280. doi: $10.2174 / 138920209788488535$

Ortega-García, F., Blanco, S., Peinado, M. A., and Peragün, J. (2008). Polyphenol oxidase and its relationship with oleuropein concentration in fruits and leaves of olive (Olea europaea) cv. 'Picual' trees during fruit ripening. Tree Physiol. 28 , 45-54. doi: 10.1093/treephys/28.1.45

Patumi, M., d'Andria, R., Fontanazza, G., Morelli, G., and Giorio, P., Sorrentino, G. (1999). Yield and oil quality of intensively trained trees culivars of olive (Olea europaea L.) under irrigation regimes. J. Hortic. Sci. Biotechnol. 74, 729-737. doi: 10.1080/14620316.1999.11511180

Patumi, M., d'Andria, R., Marsilio, V., Fontanazza, G., Morelli, G., and Lanza, B. (2002). Olive and olive oil quality after intensive monocone olive growing (Olea europaea L., cv. Kalamata) in different irrigation regimes. Food Chem. 77, 27-34. doi: 10.1016/S0308-8146(01)00317-X 
Petridis, A., Therios, I., and Samouris, G. (2012). Genotypic variation of total phenol and oleuropein concentration and antioxidant activity of 11 Greek olive cultivars (Olea europaea L.). Hortscience 47, 339-342.

Ramakrishna, A., and Ravishankar, G. A. (2011). Influence of abiotic stress signals on secondary metabolites in plants. Plant Signal Behav. 6, 1720-1731. doi: 10.4161/psb.6.11.17613

Raychaudhuri, A., and Tipton, P. A. (2002). Cloning and expression of the gene for soybean hydroxyisourate hydrolase. Localization and implications for function and mechanism. Plant Physiol. 130, 2061-2068. doi: 10.1104/pp.011049

Ripoll, J., Urban, L., Staudt, M., Lopez-Lauri, F., Bidel, L. P., and Bertin, N. (2014). Water shortage and quality of fleshy fruit making the most of the unavoidable. J. Exp. Bot. 65, 4097-4117. doi: 10.1093/jxb/eru197

Romani, A., Mulinacci, N., Pinelli, P., Vincieri, F. F., and Cimato, A. (1999), Polyphenolic content of five Tuscan cultivars of Olea europaea L. J. Agric. Food Chem. 47, 964-967. doi: 10.1021/jf980264t

Romero-Segura, C., Sanz, C., and Perez, A. G. (2009). Purification and characterization of an olive fruit $\beta$-Glucosidase involved in the biosynthesis of virgin olive oil phenolics. J. Agric. Food Chem. 57, 7983-7988. doi: 10.1021/ jf901293c

Rotondi, A., Bendini, A., Mari, L. M., Lercker, G., and Toschi, T. G. (2004). Effect of olive ripening degree on the oxidative stability and organoleptic properties of Cv. Nostrana di brisighella extra virgin olive oil. J. Agric. Food Chem. 52, 3649-3654. doi: 10.1021/jf049845a

Ryan, D., Antolovich, M., Herlt, T., Prenzler, P. D., Lavee, S., and Robards, K. (2002). Identification of phenolic compounds in tissues of the novel olive cultivar Hardy's Mammoth. J. Agric. Food Chem. 50, 6716-6724. doi: 10.1021/ jf025736p

Ryan, D., and Robards, K. (1998). Phenolic compounds in olives. Analyst 123, 31-44. doi: 10.1039/a708920a

Ryan, D., Robards, K., and Lavee, S. (1999). Change in phenolic content of olive during maturation. Int. J. Food Sci. Technol. 34, 265-274. doi: 10.1046/j.13652621.1999.00261.x

Saraiva, J., Nunes, C., and Coimbra, M. (2007). Purification and characterization of olive (Olea europaea L.) peroxidase - Evidence for the occurrence of a pectin binding peroxidase. Food Chem. 101, 1571-1579. doi: 10.1016/j.foodchem.2006. 04.012

Selvaggini, R., Esposto, S., Taticchi, A., Urbani, S., Veneziani, G., Di Maio, I., et al. (2014). Optimization of the temperature and oxygen concentration conditions in the malaxation during the oil mechanical extraction process of four Italian olive cultivars. J. Agric. Food Chem. 62, 3813-3822. doi: 10.1021/jf405753c

Selvaggini, R., Servili, M., Urbani, S., Esposto, S., Taticchi, A., and Montedoro, G. F. (2006). Evaluation of phenolic compounds in virgin olive oil by direct injection in high performance liquid chromatography with fluorometric detection. J. Agric. Food Chem. 54, 2832-2838. doi: 10.1021/jf0527596

Servili, M., Baldioli, M., Selvaggini, R., Macchioni, A., and Montedoro, J. F. (1999). Phenolic compounds of olive fruit: one-and two-dimensional Nuclear Magnetic Resonance characterization of nûzhenide and its distribution in the constitutive parts of fruit. J. Agric. Food Chem. 47, 12-18. doi: 10.1021/jf9806210

Servili, M., Esposto, S., Lodolini, E., Selvaggini, R., Taticchi, A., Urbani, S., et al. (2007a). Irrigation effects on quality, phenolic composition, and selected volatiles of virgin olive oils cv. Leccino. J. Agric. Food Chem. 55, 6609-6618.

Servili, M., Selvaggini, R., Esposto, S., Taticchi, A., Montedoro, G. F., and Morozzi, G. (2004). Health and sensory properties of virgin olive oil hydrophilic phenols: agronomic and technological aspects of production that affect their occurrence in the oil. J. Chromatogr. A 1054, 113-127. doi: 10.1016/S00219673(04)01423-2

Servili, M., Taticchi, A., Esposto, S., Sordini, B., and Urbani, S. (2012). "Technological aspects of olive oil production," in Olive Germplasm-The Olive Cultivation, Table Olive and Olive Oil Industry in Italy, ed. I. Mazzalupo (Rijeka: Intech).

Servili, M., Taticchi, A., Esposto, S., Urbani, S., Selvaggini, R., and Montedoro, G. F. (2007b). Effect of olive stoning on the volatile and phenolic composition of virgin olive oil. J. Agric. Food Chem. 55, 7028-7035.

Shao, H. B., Chu, L. Y., Jaleel, C. A., and Zhao, C. X. (2008). Water-deficit stress-induced anatomical changes in higher plants. C. R. Biol. 331, 215-225. doi: $10.1016 /$ j.crvi.2008.01.002
Sharma, P., Bhushan Jha, A., Shanker Dubey, R., and Pessarakli, M. (2012). Reactive oxygen species, oxidative damage, and antioxidative defense mechanism in plants under stressful conditions. J. Bot. 2012, 26. doi: 10.1155/2012/ 217037

Sivakumar, G., Briccoli Bati, C., and Uccella, N. (2007). Demethyloleuropein and beta-glucosidase activity in olive fruits. Biotechnol. J. 2, 381-385. doi: 10.1002/ biot. 200600118

Smith, A. T., and Veitch, N. C. (1998). Substrate binding and catalysis in heme peroxidases. Curr. Opin. Chem. Biol. 2, 269-278. doi: 10.1016/S1367-5931(98) 80069-0

Talhaoui, N., Gómez-Caravaca, A. M., Leon, L., de la Rosa, R., FernandezGutierrez, A., and Segura-Carretero, A. (2015). Pattern of variation of fruit traits and phenol content in olive fruits from six different cultivars. J. Agric. Food Chem. 63, 10466-10476. doi: 10.1021/acs.jafc.5b04315

Tamura, K., Stecher, G., Peterson, D., Filipski, A., and Kumar, S. (2013). MEGA6: Molecular Evolutionary Genetics Analysis Version 6.0. Mol. Biol. Evol. 30, 2725-2729. doi: 10.1093/molbev/mst197

Tognolli, M., Penel, C., Greppin, H., and Simon, P. (2002). Analysis and expression of the class III peroxidase large gene family in Arabidopsis thaliana. Gene 288, 129-138. doi: 10.1016/S0378-1119(02)00465-1

Tovar, M. J., Motilva, M. J., and Romero, M. P. (2001). Changes in the phenolic composition of virgin olive oil from young trees (Olea europaea L. cv. Arbequina) grown under linear irrigation strategies. J. Agric. Food Chem. 49, 5502-5508. doi: 10.1021/jf0102416

Tovar, M. J., Romero, M. P., Girona, J., and Motilva, M. J. (2002). L-Phenylalanine ammonia-lyase activity and concentration of phenolics in developing olive (Olea europaea L cv Arbequina) fruit grown under different irrigation regimes. J. Sci. Food Agric. 82, 892-898. doi: 10.1002/jsfa.1122

Tran, L. T., Taylor, J. S., and Constabel, C. P. (2012). The polyphenol oxidase gene family in land plants: lineage-specific duplication and expansion. $B M C$ Genomics 13:395. doi: 10.1186/1471-2164-13-395

Tura, D., Failla, O., Bassi, D., Pedo, S., and Serraiocco, A. (2008). Cultivar influence on virgin olive (Olea europea L.) oil flavor based on aromatic compounds and sensorial profile. Sci. Hortic. 118, 139-148. doi: 10.1016/j.scienta.2008. 05.030

Tzika, E. D., Sotiroudis, T. G., Papadimitriou, V., and Xenakis, A. (2009). Partial purification and characterization of peroxidase from olives (Olea europaea cv. Koroneiki). Eur. Food Res. Technol. 228, 487-495. doi: 10.1007/s00217-0080956-1

Veitch, N. C. (2004). Horseradish peroxidase: a modern view of a classic enzyme. Phytochemistry 65, 249-259. doi: 10.1016/j.phytochem.2003.10.022

Warzecha, H., Gerasimenko, I., Kutchan, T. M., and Stöckigt, J. (2000). Molecular cloning and functional bacterial expression of a plant glucosidase specifically involved in alkaloid biosynthesis. Phytochemistry 54, 657-666. doi: 10.1016/ S0031-9422(00)00175-8

Welinder, K. G. (1992). "Plant peroxidases: structure-function relationships," in Plant Peroxidases 1980-1990: Topics and Detailed Literature on Molecular, Biochemical, and Physiological Aspects, eds C. Penel, T. Gaspar, and H. Greppin (Geneva: University of Geneva), 1-24.

Zouari-Mechichi, H., Mechichi, T., Dhouib, A., Sami Sayadi, S., Angel, T., and Martínez, A. T. (2006). Laccase purification and characterization from Trametes trogii isolated in Tunisia: decolorization of textile dyes by the purified enzyme. Enzyme Microb. Technol. 39, 141-148. doi: 10.1016/j.enzmictec.2005. 11.027

Conflict of Interest Statement: The authors declare that the research was conducted in the absence of any commercial or financial relationships that could be construed as a potential conflict of interest.

Copyright ( 2017 Cirilli, Caruso, Gennai, Urbani, Frioni, Ruzzi, Servili, Gucci, Poerio and Muleo. This is an open-access article distributed under the terms of the Creative Commons Attribution License (CC BY). The use, distribution or reproduction in other forums is permitted, provided the original author(s) or licensor are credited and that the original publication in this journal is cited, in accordance with accepted academic practice. No use, distribution or reproduction is permitted which does not comply with these terms. 